\title{
Clonal variability for vulnerability to cavitation and other drought-related traits in Hevea brasiliensis Müll. Arg.
}

\author{
Wanploy Jinagool ${ }^{1,2}$, Ratchanee Rattanawong ${ }^{3}$, Krissada Sangsing ${ }^{4}$, Têtè Sévérien Barigah ${ }^{2,1}$, \\ Frederic Gay ${ }^{5,6}$, Hervé Cochard ${ }^{2,1}$, Poonpipope Kasemsap ${ }^{6,7}$, Stéphane Herbette ${ }^{1,2}$
}

${ }^{1}$ Université Blaise Pascal, UMR 547 PIAF, F-63177, Aubière, France; ${ }^{2}$ INRA, UMR 547 PIAF, F-63100, ClermontFerrand, France; ${ }^{3}$ Nong Khai Rubber Research Center, Rubber Research Institute of Thailand, Rattanawapi District, Nong Khai, 43120, Thailand; ${ }^{4}$ Surat Thani Rubber Research Center, Rubber Research Institute of Thailand, Thachana District, Surat Thani, 84170, Thailand; ${ }^{5}$ CIRAD, UMR Eco\&sols, F-34060, Montpellier, France; ${ }^{6}$ Hevea Research Platform in Partnership, DORAS Centre, Kasetsart University, Bangkok, 10900, Thailand; ${ }^{7}$ Department of Horticulture, Faculty of Agriculture, Kasetsart University, Bangkok, 10900, Thailand.

Correponding author: Stéphane Herbette, stephane.herbette@univ-bpclermont.fr

Date of submission: November 28, 2014 / Published: May 21, 2015

\section{Abstract}

Selection for drought-tolerant clones has become a major challenge in rubber breeding programs undertaken to ensure the sustainability of natural rubber production, as rubber plantations are expanding in drought-prone areas. Xylem vulnerability to cavitation is a trait related to drought-induced mortality. It can be rapidly evaluated without subjecting plant materials to drought stress, making it useful in large-scale screening for drought tolerance in the near future. We first compared the most widely used techniques for measuring vulnerability to cavitation (air pressurization and Cavitron) on this species, and the effect of sample conditions (size, age and sunlight exposure), in order to ensure reliable analysis. Secondly, ten rubber clones were compared for their xylem vulnerability to cavitation in branches and petioles, and for other traits related to drought response, including stomatal response and leaf shedding occurring during a simulated drought. We also tested the plasticity of vulnerability to cavitation on two clones grown in three locations with contrasting precipitation regimes. We found no clonal variability and a small phenotypic plasticity for xylem vulnerability to cavitation in branches. However, clonal differences in xylem vulnerability to cavitation were found in petioles, and clones also showed differences in stomatal response and in leaf shedding behavior in response to a simulated drought. Our study suggests a genetic canalization for vulnerability to cavitation in organs critical for survival, such as branches, whereas there are clonal differences for traits related to drought avoidance: vulnerability to cavitation of petioles, leaf shedding behavior and stomatal response. The insights gained in this study for screening rubber tree clones for drought tolerance is also discussed.

Keywords: cavitation, clonal variability, drought, embolism, Hevea brasiliensis, hydraulics, leaf shedding, stomatal conductance, xylem.

\section{Introduction}

The rubber tree (Hevea brasiliensis Muell. Arg.) is an important agricultural species. It is native to the Amazonian basin, and extensively planted in Southeast Asia. In Thailand, it was originally cultivated in the southern and eastern provinces where rainfall is abundant. However, owing to shortages of land for cultivation and competition with other crops in these regions, plantations have spread northward into northern and northeastern provinces (Fox and Castella, 2013). These areas are considered marginal for the cultivation of rubber tree in view of rainfall distribution and water availability due to poor soil 
conditions (Boithias et al., 2012). Yet in 2011, the area of rubber plantations in these marginal regions increased by 12\% compared with 2006 (RRIT, 2011). Drought stress has been reported to impair the growth of rubber trees (Chandrashekar et al., 1998; Manmuen et al., 1993) and latex production (Wichichonchai and Manmeun, 1992). Thus the northward expansion of rubber plantations can bring natural rubber production under a higher risk of drought stress. This is a real threat because extreme drought events are predicted in the years to come (Chinvanno, 2011; IPCC, 2013). Also, the use of a single rubber clone (RRIM600) in over $80 \%$ of the plantation area in Thailand further increases this risk. In this context, the selection for drought-tolerant clones has become a major challenge for rubber breeding programs to ensure yield and minimize additional costs for water management in rubber production.

Several strategies have been proposed for the selection of rubber clones suitable for cultivation in marginal areas, such as the evaluation of prominent clones and polyclonal seedlings, recombination breeding and selection, and the evaluation of Brazilian germplasm (Priyadarshan and Goncalves, 2003). The selection of rubber tree is time-consuming because it is strongly limited by non-synchronous flowering, low fruit setting, a long juvenile period, and the heterozygous nature of rubber trees (Venkatachalam et al., 2007). Hence there is a need for early screening tests for drought tolerance to speed up the process of progeny testing and produce genetic material adapted to the climatic conditions in the coming decades. Previous studies have shown high polymorphism in wild and cultivated rubber populations (Besse et al., 1994; Lekawipat et al., 2003), differences in growth (Chandrashekar et al., 1998) and yield potential (Priyadarshan et al., 2005) in rubber clones from several sub-optimal areas. Variability in drought tolerance can thus be expected in rubber clones.

Xylem sap is normally transported under tension (Dixon and Joly, 1895), which puts xylem sap in a metastable state. Under drought, this tension is exacerbated and the xylem sap can rapidly change into vapor (embolism) and cause cavitation of the xylem (Tyree and Sperry, 1989). This drought-induced cavitation may lead to a reduction in water transport and cause organ or plant death (Barigah et al., 2013). Xylem vulnerability to cavitation is considered an important trait determining drought tolerance in woody species (Choat et al., 2012). It ranges widely across the species and correlates with drought tolerance of the species (Maherali et al., 2004; Pockman and Sperry, 2000; Tyree et al., 2003). Within-species variation of xylem vulnerability to cavitation has been observed in several forest species; the diversity may be due to genetic control (Cochard et al., 2007; Wortemann et al., 2011) or a result of plant adjustment to the environmental conditions (Awad et al., 2010; Corcuera et al., 2011; Herbette et al., 2010). The xylem vulnerability to cavitation also varies between plant organs (Tyree et al., 1993), indicating vulnerability segmentation, which allows the plant to discard expendable organs in order to preserve critical ones (Zimmermann, 1983). Small genetic differences are observed between natural populations of some forest species (Lamy et al., 2011; Wortemann et al., 2011), which is interpreted as a genetic canalization for this trait, i.e. a reduction in phenotypic variability regardless of genetic variability. For agricultural species, the genetic variation of xylem vulnerability to cavitation remains to be tested, as these have undergone selection pressure different from natural species (Gepts, 2004; Purugganan and Fuller, 2009).

Various techniques have been developed to estimate xylem vulnerability to cavitation; the recent and most rapid techniques include Cavitron centrifugation (Cochard et al., 2005) and air-injection (Ennajeh et al., 2011). These methods allow the estimation of xylem vulnerability to cavitation on plant segments without subjecting plants to drought stress, and so significantly reduce experimentation time. However, there is an ongoing debate on the reliability of these techniques especially with long-vessel species (Choat et al., 2010; Cochard et al., 2010; Cochard et al., 2013; Delzon and Cochard, 2014; Ennajeh et al., 2011; Jacobsen and Pratt, 2012; Sperry et al., 2012; Tobin et al., 2013; Torres-Ruiz et al., 2014).

In this study, we firstly investigated genetic variability in xylem vulnerability to cavitation in ten commercialized rubber clones used in Thailand, and looked at the environmental plasticity of this trait in two clones from three locations that differ in mean annual precipitation. Secondly, we compared the responses of the clones to drought stress. Before investigating vulnerability to cavitation, we tested the reliability of two techniques, Cavitron and airinjection, on rubber tree branches, and the effects of plant material properties (sample length, sunlight exposure and age) on the vulnerability curves. This is a prerequisite to choosing the most suitable and accurate method to assess xylem vulnerability to cavitation in H. brasiliensis.

\section{Materials and Methods}

\section{Plant materials}

The studies were conducted using plant materials from three different locations in Thailand: $i$ ), Khon Kaen $\left(16^{\circ} 48^{\prime} 21^{\prime \prime} \mathrm{N}, 103^{\circ} 08^{\prime} 22^{\prime \prime E}\right.$; altitude $\left.252 \mathrm{~m}\right)$, (ii) Nong Khai $\left(18^{\circ} 09^{\prime} 30^{\prime \prime} \mathrm{N}, 103^{\circ} 09^{\prime} 31^{\prime \prime E}\right.$; altitude $\left.171 \mathrm{~m}\right)$, and (iii) Surat Thani $\left(9^{\circ} 40^{\prime} 27^{\prime \prime} \mathrm{N}, 99^{\circ} 6^{\prime} 40^{\prime \prime E}\right.$; altitude $\left.19 \mathrm{~m}\right)$. The first two locations are situated in the northeastern region of Thailand whereas the latter location is in the 
southern region. They had contrasting average annual rainfall and dry season length; defined as the number of months with less than $50 \mathrm{~mm}$ of rain (Webster and Baulkwill, 1989). At Surat Thani, the rainfall regime is considered non-limiting for rubber trees, with an annual rainfall of $1,800 \mathrm{~mm}$ and dry conditions of only one to two months per year. The annual rainfall of Khon Kaen and Nong Khai are 1,200 $\mathrm{mm}$ and $1,600 \mathrm{~mm}$, respectively with a dry season of five to six months (Thai Meteorological Department, 2014). These two locations are considered to be in a marginal area for natural rubber production, because rubber trees require more than $1,250 \mathrm{~mm}$ of annual rainfall with 120-150 rainy days per year for optimal growth and production (RRIT, 2012).

The experiment can be divided into two main studies: the investigation of the variation of xylem vulnerability to cavitation and the analysis of plant response to drought stress.

For the investigation of the variation of xylem vulnerability to cavitation, we firstly investigated the reliability of the techniques and the effects of sample properties on three commercial clones (PB 235, RRIM 600 and RRIT 251) grown at Surat Thani site. Branches were collected on April 2012 from three to four individual trees for each test and each condition. Table 1 describes the samples used for comparing analytical methods (Cavitron versus air-pressure) and for testing effects of sample ages (current year and previous year branches), sunlight exposure (shaded and sun-exposed) and sample size. Then after, genetic diversity and environmental plasticity of xylem vulnerability to cavitation were investigated. The study of genetic variability was conducted on ten commercial rubber clones: BPM 24, PB 217, PB 235, PB 260, PB 5/51, RRII 105, RRII 118, RRIM 600, RRIT 251 and RRIT 408. Clones $(n=12-15$ trees/clone) were grafted on RRIM 600 rootstocks and planted in the field at Nong Khai site in October 2012. On March, 2013, current year branches ( $n=6-8 /$ clone) were harvested from these trees. The study of environmental plasticity was carried out using branches of two clones (RRIM 600 and RRIT 251) from all three indicated sites. At each location, ten current year branches from the fully sun-exposed side of the canopy were harvested for each clone from oneto two-year old trees on November 2013.

In the study of plant response to drought stress, the stress was carried out on the same ten rubber tree clones used for investigating the genetic variability of xylem vulnerability to cavitation. The trees used in this experiment were also grafted on RRIM 600 rootstocks, but were individually planted in $0.93 \mathrm{~m}^{2}$ pots filled with sandy loam soil at Nong Khai site on October 2012. Each clone consisted of six replicates later divided into two groups of watering regimes: control and stress groups. During the growing period, each tree was watered to full field capacity with 15 liters twice a week until December 7 2012. Drought stress was then applied to the trees in the stress group by withholding the water supply, leaving the soil to dry down. The control trees were kept growing under full field capacity. Drought stress lasted for 11 weeks until high level of xylem embolism in petioles was reached, and on March 202013 watering was resumed for the stressed trees. During the drought experiment, occasional rains were strictly controlled by portable covering systems. They were installed to cover the pots before the rain came on, and removed promptly afterward to prevent the temperature rising in the pots.

\section{Methods}

\section{The study of xylem vulnerability to cavitation}

After severing, branch segments $0.60 \mathrm{~m}$ long were immediately defoliated and prepared for shipping to France for the analysis of xylem vulnerability to cavitation. The defoliated leaves from branches used for the study of genetic variability ( $n=40 /$ clone) were collected and measured for leaf mass per unit area (LMA). Branches were prepared for the shipping to France for the analysis of xylem vulnerability to cavitation by covering their ends with paraffin, treating them with pesticide, and sealing them in transparent plastic bags. These bags were then packed in cartons with packaging buffer and sent to France by air in ambient temperature. It took approximately one week for the package to arrive in France. On arrival, native embolism was measured on six randomly chosen branches. This is a prerequisite measurement proposed and explained by Awad et al. (2010). The remaining branches were rewrapped with moist paper, placed in a plastic bag and carton, and stored at $4^{\circ} \mathrm{C}$. Branches were brought out of cool storage just long enough for a daily analysis of xylem vulnerability to cavitation by Cavitron or air-injection. These procedures are considered a standard protocol for the sampling and sample preparation, and were applied for all other branch samplings for xylem vulnerability to cavitation measurement in this study.

\section{Native embolism}

When branches arrived at the laboratory in France, native embolism was immediately measured. For the samples designated for tests of techniques and sample properties, six branches were randomly chosen for this measurement. For the study of genetic variability and environmental plasticity, $20(n=2 /$ clone $)$ and 18 branches ( $n=3$ /clone/location) were randomly chosen. The remaining branches were rewrapped with moist paper and stored at $4{ }^{\circ} \mathrm{C}$. The maximum storage time before branches were measured for the vulnerability to cavitation for three experiments was 7, 10 and 30 days. 
Native embolism was measured with Xyl'EM (Bronkhorst, France) following the procedure described by Cruiziat et al. (2002). A segment $0.10 \mathrm{~m}$ long was harvested from the central part of the branches; it was cut under water to prevent air from entering xylem conduits and causing artificial embolism. The proximal end of the segment was attached to the hydraulic apparatus, and a solution containing $10 \mathrm{mM} \mathrm{KCl}$ and $1 \mathrm{mM} \mathrm{CaCl}_{2}$ was perfused through the segment. Initial hydraulic conductance $\left(K_{\mathrm{i}}\right)$ and maximum hydraulic conductance $\left(K_{\max }\right)$ were then measured successively under low pressure $(6-9 \mathrm{kPa})$. Before $K_{\max }$ was measured, the emboli were removed by applying a series of $3 \mathrm{~min}$ flushes $(0.15 \mathrm{MPa})$ with the $10 \mathrm{mM} \mathrm{KCl}$ and $1 \mathrm{mM} \mathrm{CaCl} 2$ solution. The percentage loss of xylem conductivity (PLC) was calculated by:

$$
P L C=100 \times\left(1-\frac{K_{i}}{K_{\max }}\right)
$$

\section{Branch xylem vulnerability to cavitation}

The measurement of xylem vulnerability to cavitation on rubber branches was made using the Cavitron centrifuge technique (Cochard, 2002; Cochard et al., 2005) and the 'pressure sleeves' air-injection technique (Ennajeh et al., 2011). All the investigations on xylem vulnerability to cavitation in branches used the Cavitron technique. The analysis of genetic variability to cavitation in ten rubber clones was measured on branch segments $0.37 \mathrm{~m}$ long. The analysis of environmental plasticity was carried out with segments $0.41 \mathrm{~m}$ long. The small difference in sample size between the two experiments was due to a change in the rotors of the Cavitron we used, which differed in diameter $(0.38$ and $0.42 \mathrm{~cm}$, respectively).

Branches were peeled to remove the bark containing the laticifer and so prevent latex exudation that could block the xylem vessels during the measurement. They were successively cut to the desired length, and branches were then infiltrated with compressed air $(0.10 \mathrm{MPa})$ at one end of the segment while the other end was submerged in water. This was done to check for vessels open at both ends in the segments (Ewers and Fisher, 1989; Zimmermann and Jeje, 1981). If vessels are open at both ends, air bubbles are observed at the submerged end. Only branch segments with no open vessels were used for the analysis of vulnerability to cavitation. This was to exclude the reported effect of the open vessel artifact on the vulnerability curve when using Cavitron (Cochard et al., 2013; Delzon and Cochard, 2014; Torres-Ruiz et al., 2014).

The Cavitron technique uses centrifugal force to increase the tension in vessels, while measuring the decrease in hydraulic conductance. Xylem pressure $(P)$ was set to a reference pressure $(-0.75 \mathrm{MPa})$ and the $K_{\max }$ value was first measured. The tension was then increased by either -0.25 or $-0.50 \mathrm{MPa}$, and new 4 sample conductance $\left(K_{\mathrm{i}}\right)$ was measured. PLC was computed using Equation (1). These procedures were repeated until sample PLC reached more than $80 \%$. The vulnerability curve (VC) was then constructed by plotting PLC versus $P$ and fitting with a sigmoid function (Pammenter and Van der Willigen, 1998):

$$
P L C=\frac{100}{1+e^{\left(\frac{s}{25 \times\left(P-P_{50}\right)}\right)}}
$$

The pressure inducing $50 \%$ loss of xylem conductivity $\left(P_{50}, \mathrm{MPa}\right)$ and the slope of the $\mathrm{VC}(s)$ were determined from the fitted sigmoid curve. The xylem tension causing $12 \%$ and $88 \%$ loss of xylem conductivity $\left(P_{12}\right.$ and $P_{88}$, respectively $)$ were calculated as:

$$
\begin{aligned}
& P_{12}=P_{50}+\frac{50}{s}, \\
& P_{88}=P_{50}-\frac{50}{s} .
\end{aligned}
$$

$P_{12}$ is considered as the 'air entry point' in which the embolism begins (Sparks and Black, 1999; $P_{88}$ is the tension before xylem becomes totally non-conductive or 'full embolism point' (Domec, 2001).

For the air-injection technique, a pressure sleeve was made up of three-way steel tubes from Swagelok Company $(2.50 \mathrm{~cm}$ in diameter and $7.50 \mathrm{~cm}$ long). It was applied to the middle of a branch segment $0.37 \mathrm{~m}$ long. Bark was peeled off at the center of the branch to create a contact surface $(3.50 \mathrm{~cm}$ long $)$ with compressed air inside the chamber. This surface allows the air to enter the xylem and induces xylem embolism (Ennajeh et al., 2011). The distal end of the branch segment was attached to a vertical plastic tube filled with a solution of $10 \mathrm{mM} \mathrm{KCl}$ and $1 \mathrm{mM} \mathrm{CaCl}_{2}$, while a plastic tube filled with cotton was placed at the proximal end to collect the solution flowing through the sample. Embolism was induced by increasing air pressure in the chamber sleeves. The hydraulic conductance $(K)$ was calculated as:

$$
K=\frac{F}{P} \text {, }
$$

where $F$ is the flow rate through sample calculated as the weight of water collected for $1 \mathrm{~min}$, and $P$ is the solution pressure in the vertical plastic tube connected to the sample. PLC was calculated using Equation (1). Air pressure in the chamber was increased stepwise until more than $90 \%$ PLC was achieved. The VC was constructed by plotting PLC versus $P$ and then fitting with sigmoid curve using Equation (2). The characteristics of the xylem vulnerability to cavitation $\left(P_{12}, P_{50}, P_{88}\right.$ and $\left.s\right)$ were calculated.

\section{Petiole vulnerability to cavitation}

Native embolism was measured on the field in petioles bearing the leaflets used for the $\Psi_{\mathrm{md}}$ measurements, in all trees. Measurements were performed on a segment 
$0.05 \mathrm{~m}$ long harvested from the central part of the petiole segment as described above for branches. Petiole vulnerability to cavitation was determined by plotting the native embolism values versus $\Psi_{\mathrm{md}}$ measured on the same leaves, as drought stress progressed. Data was fitted with the sigmoid function following Equation (2), $P_{50}$ and $s$ were extracted from the fitted curve and $P_{12}$ and $P_{88}$ were later calculated using Equations (3) and (4), respectively.

\section{The study on plant response to drought stress}

During the dry-down experiment, changes in traits of interest (soil water content, leaf water traits, and leaf and growth traits) were measured.

\section{Soil water content}

To follow the progression of drought stress, 101.38 $\mathrm{cm}^{3}$ of soil was collected at depth $0.30 \mathrm{~m}$ and $0.60 \mathrm{~m}$ from each pot. The soil was weighed and oven-dried at $105^{\circ} \mathrm{C}$ for 24 hours, and its dry weight was measured. Soil water content (SWC) was calculated as: $\mathrm{SWC}=$ $100 \times$ (fresh weight - dry weight $) /$ dry weight. The sampled soil was returned to the pots after each measurement of SWC to maintain soil volume in the pot.

\section{Leaf water traits}

The minimum stomatal conductance $\left(g_{\mathrm{s}}, \mathrm{mmol} \mathrm{m} \mathrm{m}^{-2} \mathrm{~s}^{-1}\right)$ and the midday leaf water potential $\left(\Psi_{\mathrm{md}}, \mathrm{MPa}\right)$, were measured one to two times a month with a porometer (AP4, Delta-T Device, Cambridge, U.K.) and a pressure chamber (plant water status console model 3005F1, Soilmoisture Equipment Corp., CA.), respectively. These two traits were measured between 12:00 and 14:00 under full sunlight conditions. The value of $g_{\mathrm{s}}$ was measured on three leaflets from three individual compound leaves situated at the lowest level of leaf flush on each tree. We made sure that the measurements were conducted on the leaves located at a relatively similar position on every tree. When there was no more leaf at the lowest level on a tree, the measurements were moved up to a higher position for all trees. The relative stomatal conductance $\left(g_{\mathrm{s}} / g_{\mathrm{s} \max }\right.$, $\%$ ) was calculated: $g_{\mathrm{s}}$ was the minimum stomatal conductance from stressed trees, and $g_{\mathrm{s}} \max$ was the minimum stomatal conductance averaged from the control trees, both $g_{\mathrm{s}}$ and $g_{\mathrm{s} \max }$ being measured on the same day. Following the $g_{\mathrm{s}}$ measurement, one of the compound leaves on a tree was chosen; it was covered with a plastic bag along with its petiole and removed for the measurement of $\Psi_{\mathrm{md}}$ and PLC. A segment of petiole at least $0.10 \mathrm{~m}$ long was cut and kept under tap water for measurement of the petiole PLC as described below. The remainder the leaf in the plastic bag was immediately placed in a pressure chamber for the $\Psi_{\mathrm{md}}$ measurements.
We plotted gs /gs max versus $\Psi$ md and fitted these data with the sigmoid function according to Equation (2) to calculate the water potential causing $50 \%$ of stomatal closure (gs 50). Water potentials causing $12 \%$ and $88 \%$ of stomatal closure (gs 12 and gs 88 , respectively) were then calculated using Equations (3) and (4).

\section{Leaf and growth traits}

For each clone, leaf area was measured on 40 leaves using a leaf area meter (LI-3000A, LI-COR Inc.), and a mean leaf size was calculated. Ten of these leaves were then used to measure leaf mass per unit area (LMA). Their dry mass was measured after drying them at $70^{\circ} \mathrm{C}$ for 48 hours in a gravity convection oven. The LMA was calculated as the ratio of leaf dry weight to leaf area.

During the experiment, the number of leaves and the tree height were recorded every four weeks. The total leaf area of the tree was estimated based on the number of leaves, and the leaf size averaged for each clone. Accumulated shed leaf area was determined for each tree, and the relative shed leaf area (LS) was calculated. The LS was expressed as the droughtinduced leaf shedding compared with leaf shedding observed on control trees. LS was then plotted against $\Psi_{\text {md }}$ and fitted with the sigmoid function according to Equation (2). We then calculated the xylem tension (MPa) that caused $12 \%, 50 \%$ and $88 \%$ of leaf shedding $\left(\mathrm{LS}_{12}, \mathrm{LS}_{50}\right.$ and $\mathrm{LS}_{88}$, respectively). The growth rate (GR) was calculated from the slope of the logarithm of height versus time over the 11 weeks of drought stress.

\section{Hydraulic safety margins}

The hydraulic safety margin of a plant can be determined using various traits involving the threshold tensions for safety and efficiency in xylem conduits (Choat et al., 2012; Markesteijn et al., 2011; Meinzer et al., 2009). In this study, we determined the hydraulic safety margins for petiole and branch according to the following hypotheses: (i) stomatal regulation prevents petiole xylem from reaching a threshold tension inducing cavitation, and (ii) droughtinduced leaf shedding helps preserve the branch from embolism. The petiole safety margin was calculated as the difference between the xylem pressure at $g_{\text {s } 50}$ and the $P_{50}$ of the petiole. The safety margin of the branch was calculated as the difference between $\mathrm{LS}_{50}$ and the $P_{50}$ of the branch.

\section{Statistics}

Analysis of variance (ANOVA) was used to test the effects of the following factors on the xylem vulnerability to cavitation: techniques (Cavitron versus air-injection), lengths of branch segment $(0.27 \mathrm{~m}$, $0.37 \mathrm{~m}$ and $0.41 \mathrm{~m}$ ), light exposures (shaded and fully exposed), sample ages (current and previous year 
branches), clones and water availability in plantations. ANOVA was also used to test the effect of water deficit treatment on the following traits: SWC, $\Psi_{\mathrm{md}}, g_{\mathrm{s}}$ $/ g_{\mathrm{s} \max }$, PLC, LS, safety margin of the branch and petiole, and GR. When significant differences were found, we performed the Tukey-Kramer multiple comparison at $95 \%$ confidence interval.

\section{$\underline{\text { Results }}$}

\section{Reliability of Cavitron and air-injection techniques and the effects of sample properties}

Native embolism measured on three sets of branches indicated a rather low native embolism with a mean of $15.61 \%$ ( $\mathrm{SE} \pm 1.54)$. No significant difference was found either within or between sampling sets. When the segments were infiltrated with compressed air at one end, we observed air bubbles at the other end on some of the $0.37 \mathrm{~m}$ segments, but no air bubbles were observed on any $0.41 \mathrm{~m}$ segments. These results indicate that the vessel length of these rubber trees was less than $0.41 \mathrm{~m}$ and occasionally longer than $0.37 \mathrm{~m}$. Only the segments $0.37 \mathrm{~m}$ long without vessels cut open at both ends were measured for xylem vulnerability to cavitation.

Xylem vulnerability to cavitation of branches was assessed using two techniques: Cavitron and air- injection with $0.37 \mathrm{~m}$ branch segments (Table 1). Both techniques gave sigmoid vulnerability curves with similar values of $P_{12}, P_{50} P_{88}$ and $s$. However, a wider variation between repetitions was observed when using the air-injection technique.

The results for effects of sample properties on vulnerability to cavitation are shown in Table 1 . The average $P_{50}$ values of branches were -1.86 , and -1.87 $\mathrm{MPa}$ for the 0.37 and $0.41 \mathrm{~m}$ segments, and $-0.93 \mathrm{MPa}$ for the $0.27 \mathrm{~m}$ long segments. Branches of the current year had a significant lower $P_{50}$ than those of the previous year $(-1.77$ vs. $-1.88 \mathrm{MPa}$, respectively), showing an effect of sample age. Branches fully exposed to sunlight and shaded branches had similar $P_{50}$ values $(-1.90$ and $-1.88 \mathrm{MPa}$, respectively).

\section{Variability of xylem vulnerability to cavitation on branches of $\boldsymbol{H}$. brasiliensis}

The branch $P_{50}$ values of the ten rubber clones studied were not statistically different, and ranged from -1.73 to $-2.02 \mathrm{MPa}$ (Figure $1 A$ ). No significant difference was found in $P_{12}$ and $P_{50}$ measured on branch samples between the three locations (Khon Kaen, Nong Khai and Surat Thani), and significant differences were observed only between the most sharply contrasting values of $P_{88}$ at Nong Khai and Surat Thani (-2.63 \pm 0.11 and $-2.28 \pm 0.09 \mathrm{MPa}$, respectively) (Figure $1 B)$.

Table 1: Xylem vulnerability to cavitation $\left(P_{50}\right)$ obtained from two analytical methods and different sample properties.

\begin{tabular}{|c|c|c|c|}
\hline Conditions & $P_{50}(\mathrm{MPa})$ & $n$ & sample properties \\
\hline $\begin{array}{l}\text { Technique } \\
\text { - Cavitron } \\
\text { - Air-injection }\end{array}$ & $\begin{array}{ll}-1.86 & (0.05) \\
-1.89 & (0.15)\end{array}$ & $\begin{array}{l}5 \\
4\end{array}$ & $\begin{array}{l}0.37 \mathrm{~m} \text { long, current year branches from PB 235, RRIM } \\
600 \text { and RRIT 251, fully exposed to sunlight. }\end{array}$ \\
\hline $\begin{array}{l}\text { Cavitron: Sample ages } \\
\text { - Current year branch } \\
\text { - Previous year branch }\end{array}$ & $\begin{array}{l}-1.77^{a}(0.04) \\
-1.88^{b}(0.01)\end{array}$ & $\begin{array}{l}5 \\
6\end{array}$ & $\begin{array}{l}0.37 \text { m long branches from RRIM } 600 \text { and RRIT } 251 \text {, } \\
\text { fully exposed to sunlight. }\end{array}$ \\
\hline $\begin{array}{l}\text { Cavitron: Sunlight exposure } \\
\text { - Shaded } \\
\text { - Sun-exposed }\end{array}$ & $\begin{array}{ll}-1.88 & (0.03) \\
-1.90 & (0.03)\end{array}$ & $\begin{array}{l}5 \\
5\end{array}$ & $0.37 \mathrm{~m}$ long, current year branches of PB 235 . \\
\hline $\begin{array}{l}\text { Cavitron: Sample size } \\
\begin{array}{l}\cdot 0.27 \mathrm{~m} \\
-0.37 \mathrm{~m} \\
\\
\cdot 0.41 \mathrm{~m}\end{array}\end{array}$ & $\begin{array}{l}-0.94^{a}(0.04) \\
-1.86^{b}(0.02) \\
-1.87^{b}(0.04)\end{array}$ & $\begin{array}{c}4 \\
14\end{array}$ & $\begin{array}{l}\text { Branches of current year and fully exposed to sunlight } \\
\text { from: } \\
\text {-RRIM } 600 \text { with PB } 217 . \\
\text {-Ten clones (BPM 24, PB 217, PB 235, PB 260, PB } \\
\text { 5/51, RRII 105, RRII 118, RRIM600, RRIT } 251 \text { and } \\
\text { RRIT 408). } \\
\text {-RRIM } 600 \text { and RRIT } 251 .\end{array}$ \\
\hline
\end{tabular}

The variation in water potential inducing 50\% loss of conductivity $\left(P_{50}\right)$ was measured for branches from seven to ten years old rubber trees grown at the Surat Thani Rubber Research Centre in the southern region of Thailand $\left(9^{\circ} 40^{\prime} 27^{\prime \prime} \mathrm{N}, 9^{\circ} 6^{\prime} 40^{\prime \prime} \mathrm{E}\right.$; altitude $19 \mathrm{~m})$. Branches were collected from three to four individual trees for each test and each condition. The comparisons were carried out for the measurement techniques (Cavitron $v s$. air-injection), the sampling conditions: sample ages (current year and previous year branches) and sunlight exposure (shaded and sun-exposed), and the effects of sample size $(0.27,0.37$ and $0.41 \mathrm{~m})$. Data are mean values with standard errors in brackets. Variable $n$ is the number of replications. Different letters indicate significant differences between means at $95 \%$ confidence interval. 

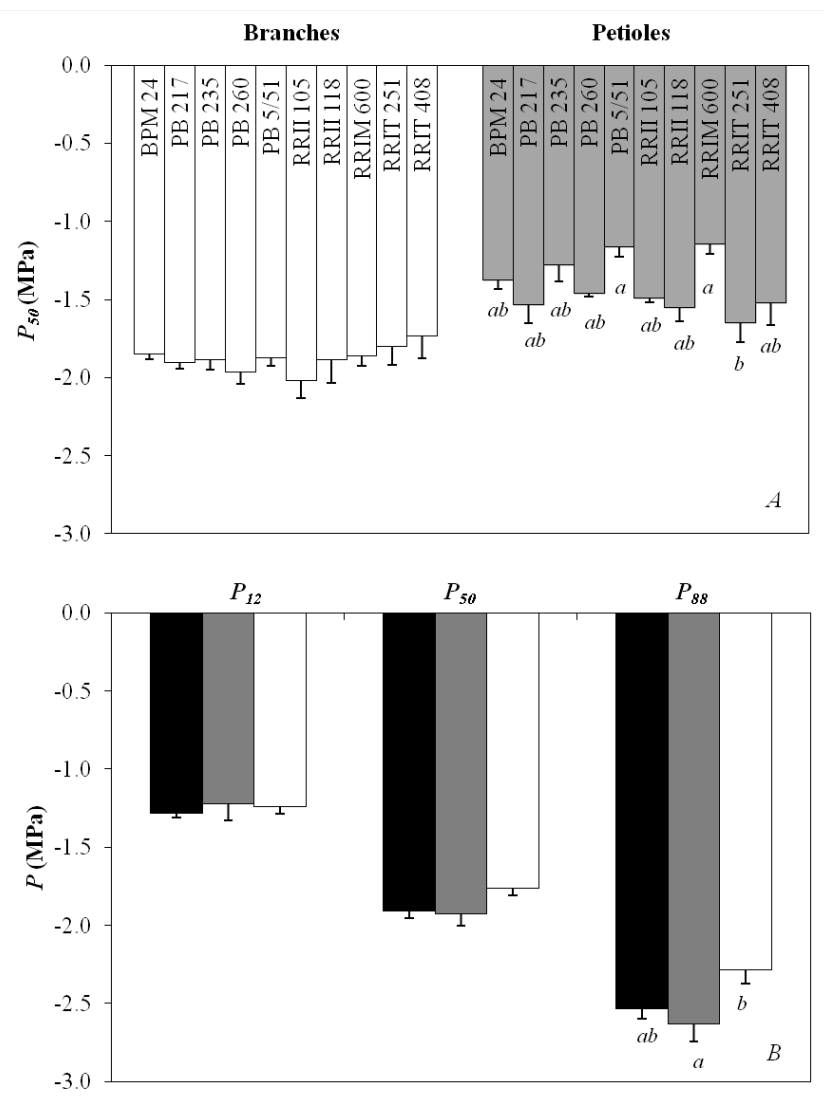

Figure 1: Clonal and environmental variabilities of xylem vulnerability to cavitation in rubber clones. $P_{50}$ was measured on $(A)$ branch and petiole samples from ten rubber clones from the same plantation at Nong Khai and $(B)$ branches of RRIM 600 and RRIT 251 collected from three locations in Thailand with different annual rainfall (in brackets): Khon Kaen (1,000-1,200 mm; black), Nong Khai (1,400-1,600 mm; grey) and Surat Thani (2,800-3,200; white). The values are clonal average $(n=3$ to 4$)$ with standard error bars. Different letters indicate significant differences at $95 \%$ confidence interval.

\section{Clone response to drought stress}

The progression of drought stress was monitored by relating SWC and $\Psi_{\mathrm{md}}$ (Figure 2). SWC declined progressively after watering was withheld (Figure $2 A$ ), and significant differences were found between stressed and control trees from week 7 onward, whereas no significant difference was found between clones at any given time. Significant differences in $\Psi_{\mathrm{md}}$ were only observed on weeks 9 and 11 for the clones, with the most sharply contrasting $\Psi_{\mathrm{md}}$ values (Figure $2 B)$.

The drought response of rubber trees was investigated for stomatal regulation $\left(g_{\mathrm{s}} / g_{\mathrm{s} \text { max }}\right)$, embolism rate (PLC) and leaf shedding (LS) (Figure 3). Before the drought stress, the $g_{s} / g_{s \text { max }}$ ranged from 83.60 to $99.76 \%$, and after the application of drought stress, declining trends in $g_{\mathrm{s}} / g_{\mathrm{s} \max }$ were observed (Figure $3 \mathrm{~A}$ ). The differences in $g_{\mathrm{s}} / g_{\mathrm{s} \text { max }}$ between clones were not significant except between RRIT $251(110.48 \% \pm 7.15)$ and RRII 118 $(36.21 \% \pm 18.83)$ on week 2 after watering was withheld. During the drought period, the PLC of the petioles increased (Figure $3 B$ ) and significant differences were found only between PB 5/51, RRIT 251 and RRIT 408 (PLC $=60.25$ to $61.50 \%$ ) compared with BPM $24(26.20 \%)$ on week 6. By week 11 of drought stress, high embolism rate occurred for all the clones (PLC $=74.98$ to $87.07 \%$ ). The relative shed leaf area (LS, \%) shows the kinetics of leaf shedding of the clones (Figure 3C). On weeks 9 and 11, significant differences were found in LS between clones; BPM 24 clearly shed a larger leaf area than the other clones.
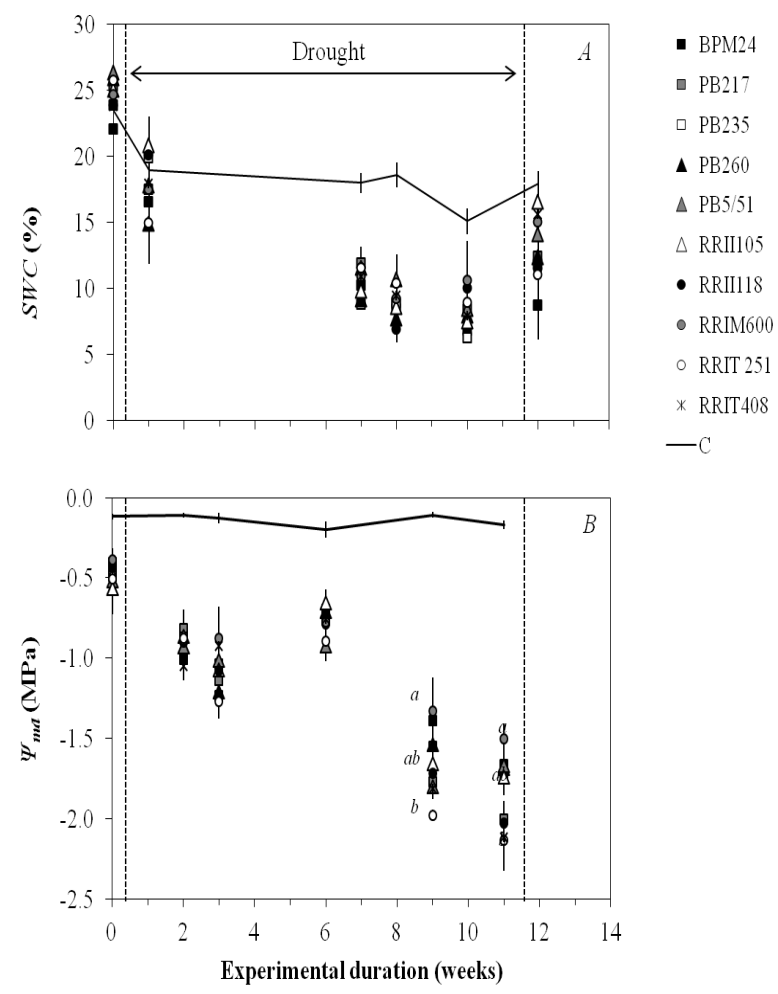

Figure 2: Survey of soil water content (SWC) and midday leaf water potential $\left(\Psi_{\mathrm{md}}\right)$ in 10 rubber clones during a drought. The solid lines indicate mean values measured on control trees $(n=30)$ and dots are mean values measured on stressed trees $(n=3)$. Bars are standard errors. Different letters indicate significant difference between clones at a given time point of the kinetics, with $95 \%$ confidence interval.

Significant differences were found in means of petiole $P_{50}$ between the clones, with a greater variation (from -1.15 to $-1.65 \mathrm{MPa}$ ) than that in branch $P_{50}$ (Figure $1 A$ ). The petioles of PB 5/51 and RRIM 600 were the most vulnerable to cavitation, whereas petioles of RRIT 251 were the least vulnerable. Petioles were still more vulnerable to cavitation than branches, with significant differences (at 95\% confidence interval) when comparing the branch $P_{50}$ values with petiole ones, except for RRII 118, RRIT 251 and RRIT 408. In Figure 4, vulnerability curves of branches and petioles are presented for RRIM 600 and RRIT 251, which had the most sharply contrasting petiole $P_{50}$ values. 

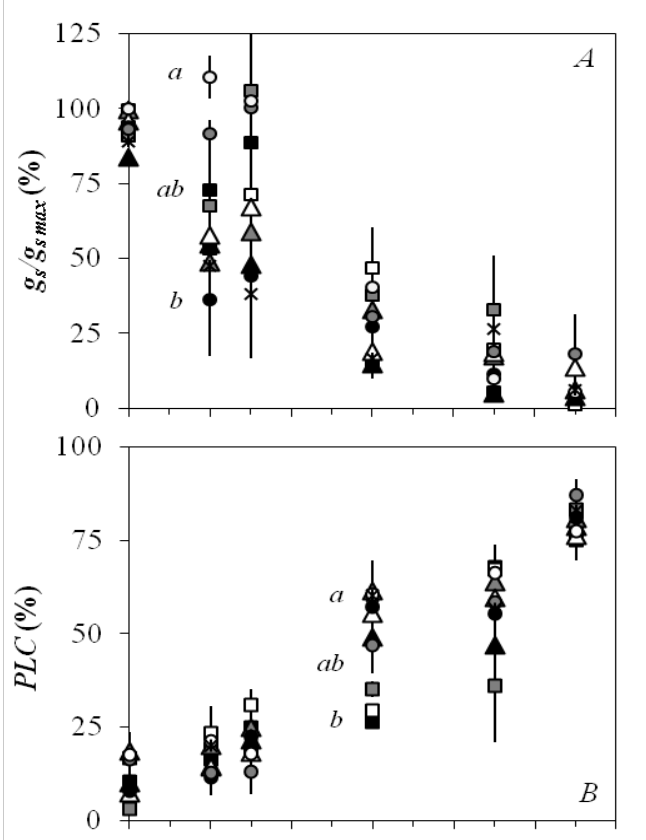

-BPM 24

$\square \mathrm{PB} 217$

$\square$ PB 235

$\triangle \mathrm{PB} 260$

$\triangle \mathrm{PB} 5 / 51$

$\triangle \mathrm{RR} I 105$

•RRII18

ORRIM 600

ORRIT 251

*RRIT 408

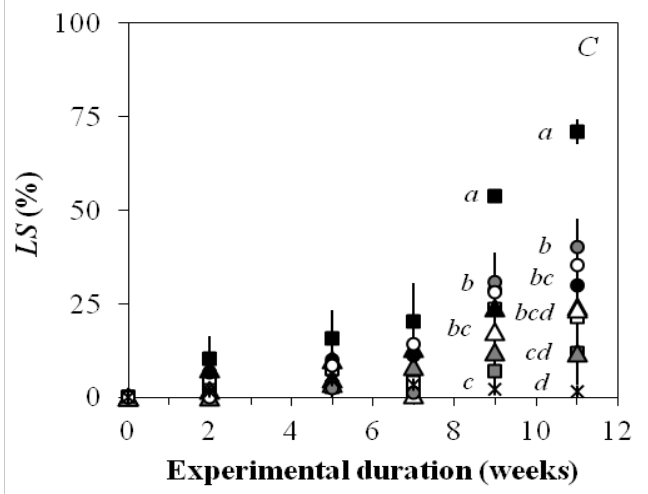

Figure 3: Survey of drought-related traits in 10 rubber clones during a simulated drought (A) Relative stomatal conductance (gs /gs max), (B) percentage loss of petiole xylem conductivity (PLC) and (C) relative shed leaf area (LS) were plotted versus drought duration (weeks). Dots represent the means $(n=3)$ and the bars are standard errors. Different letters indicate a significant difference between the clones at a given point of the kinetics, with $95 \%$ confidence interval.

The $g_{\mathrm{s} 50}(\mathrm{MPa})$ and $\mathrm{LS}_{50}$ are shown in Table 2 along with the calculated safety margins of petioles and branches. The ten clones had similar $g_{\mathrm{s} 50}$, but different $\mathrm{LS}_{50}$ values. The petiole safety margin was not significantly different between clones, whereas the safety margin of branches ranged from -1.02 to 0.54 $\mathrm{MPa}$, with significant differences between PB 217 and RRIT 408 with other clones.

Before the watering was withheld, the ranges of tree height for control and stress group were $2.67-4.49 \mathrm{~m}$ and 3.45-4.65 m, respectively. Significant differences were found for tree height between clones in the stress group, RRIM 600 trees being significantly taller (4.65 m) than PB 217, PB 260, PB5/51 and RRIT 118 trees $(\bar{x}=3.47 \mathrm{~m} \pm 11.93)$. Before drought treatment, the GR in height ranged from 0.048 to $0.179 \mathrm{~m} . \mathrm{d}^{-1}$, with no significant difference between clones. During the dry period, the GR was reduced in both control and stress conditions. The GR of control trees ranged from 0.003 to $0.122 \mathrm{~m} . \mathrm{d}^{-1}$, while the stressed trees had GR ranging from 0.004 to $0.081 \mathrm{~m} . \mathrm{d}^{-1}$, and no significant difference was observed either between clones or between watering treatments.

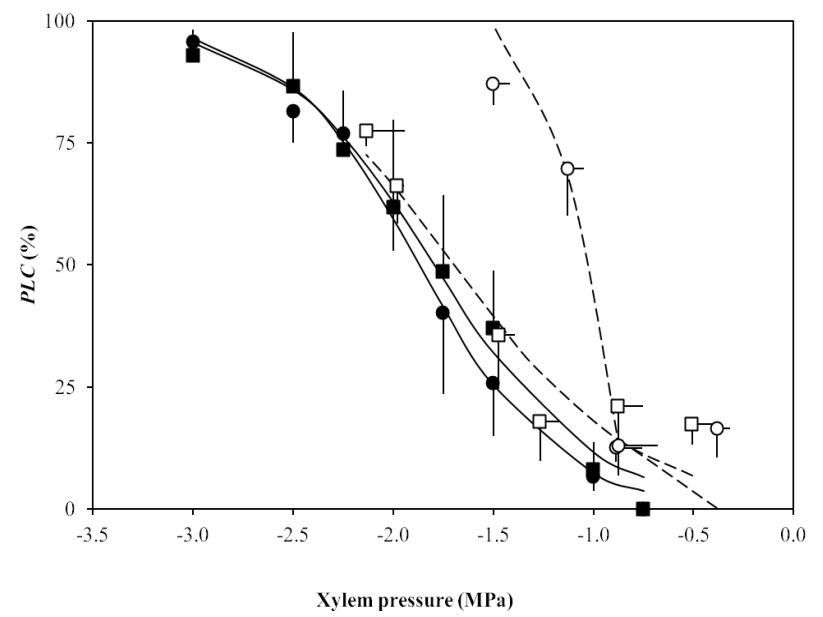

Figure 4: Xylem vulnerability curves of samples of branches (closed symbols) and petioles (open symbols) from RRIM 600 (circle) and RRIT 251 (square). Data are means values $(n=3$ or 4$)$ and bars are standard errors. Logistic lines were fitted to data using a sigmoid function.

\section{Discussion}

Xylem vulnerability to cavitation suggests itself as a suitable criterion for screening drought-tolerant clones, because it is considered as a critical trait for tolerance to severe drought and can be rapidly assessed on branches of rubber trees using the Cavitron centrifuge technique and the air-injection technique. However, the reliability of such techniques has to be tested prior to any investigations on a species. Sigmoid vulnerability curves were obtained from both techniques when using samples longer than the maximum vessel length $(0.37 \mathrm{~m}$ or $0.41 \mathrm{~m})$, whereas the $0.27 \mathrm{~m}$ segments contain vessels that were open at both ends, thus resulting in vessels abnormally vulnerable to cavitation. This results from the 'open vessel' artifact in vulnerability to cavitation (Choat et al., 2010; Cochard et al., 2010; Delzon and Cochard, 2014). The effects of age, sunlight conditions, sample size and location observed here and in other studies with different species (Cochard et al., 1999; Cochard et al., 2007; Herbette et al., 2010) highlight the importance of sample design when investigating vulnerability to cavitation. To pursue the investigation of the clonal variability and environmental plasticity of xylem vulnerability to cavitation, we thus performed the measurement on branch samples from the current year, at least $0.37 \mathrm{~m}$ long and grown under full sunlight conditions. 
Table 2: Hydraulic safety margins for petiole and branch of ten rubber clones. Values are means $(n=3)$ with standard error in the brackets. Different letters indicate significant differences between clones at $95 \%$ confidence interval.

\begin{tabular}{|c|c|c|c|c|c|c|}
\hline Clone & $\boldsymbol{g}_{\mathbf{s} \text { 50 }} \mathbf{( M P a )}$ & $\begin{array}{c}\text { Petiole } \boldsymbol{P}_{\mathbf{5 0}} \\
\mathbf{( M P a )}\end{array}$ & $\begin{array}{c}\text { Petiole safety margin } \\
\mathbf{( M P a )}\end{array}$ & $\boldsymbol{L S}_{\mathbf{5 0}} \mathbf{( M P a )}$ & $\begin{array}{c}\text { Branch } \boldsymbol{P}_{\mathbf{5 0}} \\
\mathbf{( M P a})\end{array}$ & $\begin{array}{c}\text { Branch safety } \\
\text { margin (MPa) }\end{array}$ \\
\hline BPM 24 & $-0.61(0.05)$ & $-1.37^{\mathrm{ab}}(0.06)$ & $0.77(0.02)$ & $-1.30^{\mathrm{a}}(0.08)$ & $-1.85(0.04)$ & $0.54^{\mathrm{a}}(0.08)$ \\
\hline PB 217 & $-0.96(0.05)$ & $-1.53^{\mathrm{ab}}(0.12)$ & $0.57(0.08)$ & $-2.86^{\mathrm{b}}(0.08)$ & $-1.91(0.04)$ & $-0.95^{\mathrm{b}}(0.08)$ \\
\hline PB 235 & $-1.14(0.08)$ & $-1.28^{\mathrm{ab}}(0.11)$ & $0.14(0.16)$ & $-1.68^{\mathrm{a}}(0.16)$ & $-1.88(0.07)$ & $0.20^{\mathrm{a}}(0.16)$ \\
\hline PB 260 & $-0.91(0.21)$ & $-1.46^{\mathrm{ab}}(0.03)$ & $0.55(0.18)$ & $-1.85^{\mathrm{a}}(0.11)$ & $-1.96(0.08)$ & $0.11^{\mathrm{a}}(0.11)$ \\
\hline PB 5/51 & $-0.94(0.06)$ & $-1.16^{\mathrm{a}}(0.06)$ & $0.22(0.02)$ & $-2.06^{\mathrm{ab}}(0.17)$ & $-1.87(0.05)$ & $-0.18^{\mathrm{a}}(0.17)$ \\
\hline RRII 105 & $-0.92(0.08)$ & $-1.49^{\mathrm{ab}}(0.03)$ & $0.57(0.08)$ & $-1.87^{\mathrm{a}}(0.13)$ & $-2.02(0.11)$ & $0.15^{\mathrm{a}}(0.13)$ \\
\hline RRII 118 & $-0.84(0.17)$ & $-1.55^{\mathrm{ab}}(0.09)$ & $0.71(0.20)$ & $-1.68^{\mathrm{a}}(0.12)$ & $-1.89(0.15)$ & $0.20^{\mathrm{a}}(0.12)$ \\
\hline RRIM 600 & $-0.98(0.13)$ & $-1.15^{\mathrm{a}}(0.06)$ & $0.17(0.07)$ & $-1.51^{\mathrm{a}}(0.10)$ & $-1.86(0.06)$ & $0.35^{\mathrm{a}}(0.10)$ \\
\hline RRIT 251 & $-1.35(0.25)$ & $-1.65^{\mathrm{b}}(0.13)$ & $0.30(0.33)$ & $-1.62^{\mathrm{a}}(0.27)$ & $-1.80(0.12)$ & $0.18^{\mathrm{a}}(0.27)$ \\
\hline RRIT 408 & $-0.91(0.10)$ & $-1.52^{\mathrm{ab}}(0.14)$ & $0.61(0.04)$ & $-2.75^{\mathrm{b}}(0.20)$ & $-1.73(0.14)$ & $-1.02^{\mathrm{b}}(0.20)$ \\
\hline
\end{tabular}

Branch and petiole xylem vulnerability to cavitation of rubber trees found in this study were in the same range as those previously found by Sansing et al. (2004), although the levels of vulnerability between the two organs were not in agreement. We found no difference between clones for the vulnerability to cavitation of branches, even though the clones were shown to be different for many other traits related to growth, crown architecture and latex yield (Besse et al., 1994; Chandrashekar et al., 1998; Lekawipat et al., 2003; Priyadarshan et al., 2005). The phenotypic plasticity for vulnerability to cavitation also appeared very weak for this species when comparing trees grown under contrasting environmental conditions (drought-prone versus traditional areas), as well as with different conditions of sunlight or sample age. Taken together, our results on this crop species support a genetic canalization for the vulnerability to cavitation. This canalization for xylem vulnerability to cavitation was clearly demonstrated in populations of a forest species (Lamy et al., 2011). Nevertheless, there were differences in vulnerability to cavitation between clones when considering the petiole, which is not a critical organ like the branch that carries the buds needed for survival. In addition, vulnerability to cavitation for the petiole is higher than in branches, and the difference between them varies depending on the clones. Higher vulnerability of xylem vessels in petioles than in branches indicates vulnerability segmentation, also found in other species (Tsuda and Tyree, 1997; Tyree et al., 1993). The xylem conduits in petioles being vulnerable to cavitation, they can become fully embolized at fairly high water potential, which leads to a hydraulic disconnection between leaf and branch, and weakens the tension in the branch. This ability prevents hydraulic failure in the branches and the stems, ensuring adequate water supply to buds (Barigah et al., 2013). More vulnerable conduits of petiole in rubber trees may thus be considered as an advantage for tree survival rather than a drawback. We would expect the genetic canalization for the vulnerability to cavitation to hold for critical organs bearing buds, and that the xylem vulnerability to cavitation could vary in less critical organs, as for other traits we measured here or traits measured in previous studies. This hypothesis now needs to be thoroughly investigated by testing the respective variability for branch and petiole in several species.

In addition to xylem vulnerability to cavitation, there are other traits that can delay drought-induced cavitation events in xylem. To compare clones for response to drought, we followed stomatal conductance, petiole embolism and leaf shedding for the ten clones during a drought (Figure 4), and the safety margins of petioles and branches were then calculated (Table 2). We found clear differences between clones for the stomatal closure at weeks 2 and 4 , then for the embolism level in petiole at week 6 , and later for the level of leaf shedding starting from week 9. The stomatal regulation when facing drought stress indicates isohydric behavior in the rubber tree. This finding is consistent with previous reports (Isarangkool Na Ayutthaya et al., 2011; Kobayashi et al., 2014; Kunjet et al., 2013). Although the stomatal regulation delays the occurrence of critical embolism, particularly during the onset of drought stress, it cannot completely prevent cavitation occurring, and thus it cannot be sufficient, especially in conditions of severe drought. Embolism in petioles and leaf shedding would also help in preventing hydraulic failure in branches and stem. We observed that leaf shedding after the embolism rate in petiole increased significantly, suggesting that high embolism rate would lead to leaf shedding. However, we cannot rule out the possibility that the two events are unrelated, even if both contribute to preventing hydraulic failure in branches. The petiole safety margin of 10 rubber clones ranged from 0.14 to $0.77 \mathrm{MPa}$, but there was no significant difference between them. The safety margin of branches varied from -1.02 to $0.54 \mathrm{MPa}$, and there were significant differences between mean values of PB 217 and RRIT 408 with the other clones. The 
negative or near-zero safety margins indicate that rubber trees of some clones have kept their stomata opened and their leaves attached within the full range of endurable water potential before failure of the hydraulic system. Taken together, these results show that there are clonal differences for some traits related to avoidance of drought-induced cavitation.

It is difficult to compare clones for their drought tolerance in this study, and thus the respective contribution of the different traits. The effect of drought stress on tree growth is not very apparent, and the trees are too young to compare for their latex yield. The comparison of GR between the stressed trees and the control trees showed a non-significant difference. The reason for this similar GR between control and stressed trees may be because the experiment was done during a dry season in Thailand, which is a period when the growth of the rubber tree is normally halted (Chandrashekar et al., 1998). To address this problem, further research is needed with a more severe drought and more individual trees to investigate the recovery ability.

To conclude, our study reveals that xylem vulnerability to cavitation in branches is not a strong criterion in selecting for drought tolerance in the rubber tree population studied. The variation for this trait is weak. Trade-offs between vulnerability to cavitation and growth-related traits were shown in other species (Cochard et al., 2007; Wikberg and Ögren, 2004). Here, we found for rubber trees that vulnerability to cavitation of branches did not vary in clones, whereas these largely differed in their growth and latex yield. This means that the selection programs for agronomic traits did not affect xylem vulnerability to cavitation. Further research on xylem vulnerability to cavitation should be carried out with larger populations including Brazilian rubber trees to broaden the genetic diversity beyond the widespread commercial clones. Nevertheless, considering the differences in stomatal regulation, petiole vulnerability to cavitation and leaf shedding, which indicate different desiccation avoidance behaviors between the clones, screening for drought resistance should firstly focus on these traits. The combination of the scion and the rootstock would also be a next step in investigating the drought responses of this species, especially because knowledge of rootstock responses to drought stress is still lacking for rubber trees.

\section{Acknowledgements}

The authors would like to thank all personals from The Rubber Institute of Thailand for the collaboration in field experiment. We would like also to thank the two anonymous reviewers that contributed with their corrections and suggestions.

\section{References}

Awad H., Barigah T.S., Badel E., Cochard H., Herbette S. 2010. Poplar vulnerability to xylem cavitation acclimates to drier soil conditions. Physiologia Plantarum 139:280288.

Barigah T.S., Charrier O., Douris M., Bonhomme M., Herbette S., Améglio T., Fichot R., Brignolas F., Cochard H. 2013. Water stress-induced xylem hydraulic failure is a causal factor of tree mortality in beech and poplar. Annals of Botany 112:1431-1437.

Besse P., Seguin M., Lebrun P., Chevallier M., Nicolas D., Lanaud C. 1994. Genetic diversity among wild and cultivated populations of Hevea brasiliensis assessed by nuclear RFLP analysis. Theoretical and Applied Genetics 88:199-207.

Blum A. 1988. Plant breeding for stress environments CRC Press, Inc.

Boithias L., Do F.C., Isarangkool Na Ayutthaya S., Junjittakarn J., Siltecho S., Hammecker C. 2012. Transpiration, growth and latex production of a Hevea brasiliensis stand facing drought in Northeast Thailand: the use of the WaNuLCAS model as an exploratory tool. Experimental Agriculture 48:49-63.

Chandrashekar T., Nazeer M., Marattukalam J., Prakash G., Annamalainathan K., Thomas J. 1998. An analysis of growth and drought tolerance in rubber during the immature phase in a dry subhumid climate. Experimental Agriculture 34:287-300.

Chinvanno S. 2011. Developing Regional Climate Change Scenario and Dilemma in Climate Change Adaptation Planning. Southeast Asia SysTem for Analysis, Research and Training (START) Regional Center, Bangkok, Thailand.

Choat B., Drayton W.M., Brodersen C., Matthews M.A., Shackel K.A., Wada H., McElrone A.J. 2010. Measurement of vulnerability to water stress-induced cavitation in grapevine: a comparison of four techniques applied to a long-vesseled species. Plant, Cell \& Environment 33:1502-1512.

Choat B., Jansen S., Brodribb T.J., Cochard H., Delzon S., Bhaskar R., Bucci S.J., Feild T.S., Gleason S.M., Hacke U.G. 2012. Global convergence in the vulnerability of forests to drought. Nature.

Cochard H. 2002. A technique for measuring xylem hydraulic conductance under high negative pressures. Plant, Cell \& Environment 25:815-819.

Cochard H., Lemoine D., Dreyer E. 1999. The effects of acclimation to sunlight on the xylem vulnerability to embolism in Fagus sylvatica L. Plant, Cell and Environment 22:101-108.

Cochard H., Casella E., Mencuccini M. 2007. Xylem vulnerability to cavitation varies among poplar and willow clones and correlates with yield. Tree Physiology 27:1761-1767.

Cochard H., Damour G., Bodet C., Tharwat I., Poirier M., Améglio T. 2005. Evaluation of a new centrifuge technique for rapid generation of xylem vulnerability curves. Physiologia Plantarum 124:410-418.

Cochard H., Herbette S., Barigah T., Badel E., Ennajeh M., Vilagrosa A. 2010. Does sample length influence the shape of xylem embolism vulnerability curves? A test with the Cavitron spinning technique. Plant, Cell \& Environment 33:1543-1552. 
Cochard H., Badel E., Herbette S., Delzon S., Choat B., Jansen S. 2013. Methods for measuring plant vulnerability to cavitation: a critical review. Journal of Experimental Botany 64:4779-4791.

Corcuera L., Cochard H., Gil-Pelegrin E., Notivol E. 2011. Phenotypic plasticity in mesic populations of Pinus pinaster improves resistance to xylem embolism (P50) under severe drought. Trees 25:1033-1042.

Cruiziat P., Cochard H., Améglio T. 2002. Hydraulic architecture of trees: main concept and results. Ann. For. Sci. 59:723-752.

Delzon S., Cochard H. 2014. Recent advances in tree hydraulics highlight the ecological significance of the hydraulic safety margin. New Phytologist.

Dixon H.H., Joly J. 1895. On the ascent of sap. Philosophical Transactions of the Royal Society of London. B:563-576.

Domec J.C. 2001. Cavitation and water storage capacity in bole xylem segments of mature and young Douglas-fir trees. Trees 15:204-214.

Ennajeh M., Nouiri M., Khemira H., Cochard H. 2011. Improvement to the air-injection technique to estimate xylem vulnerability to cavitation. Trees - Structure and Function:1-6.

Ewers F.W., Fisher J.B. 1989. Techniques for measuring vessel lengths and diameters in stems of woody plants. American Journal of Botany:645-656.

Fox J., Castella J.-C. 2013. Expansion of rubber (Hevea brasiliensis) in Mainland Southeast Asia: what are the prospects for smallholders? The Journal of Peasant Studies 40:155-170.

Gepts P. 2004. Crop domestication as a long-term selection experiment. Plant Breeding Reviews 24:1-44.

Herbette S., Wortemann R., Awad H., Huc R., Cochard H., Barigah T.S. 2010. Insights into xylem vulnerability to cavitation in Fagus sylvatica L.: phenotypic and environmental sources of variability. Tree Physiology 30:1448-1455.

IPCC. 2014. Climate Change 2014: Impacts, Adaptation, and Vulnerability. Part B: Regional Aspects. Contribution of Working Group II to the Fifth Assessment Report of the Intergovernmental Panel on Climate Change [Barros, V.R., C.B. Field, D.J. Dokken, M.D. Mastrandrea, K.J. Mach, T.E. Bilir, M. Chatterjee, K.L. Ebi, Y.O. Estrada, R.C. Genova, B. Girma, E.S. Kissel, A.N. Levy, S. MacCracken, P.R. Mastrandrea, and L.L. White (eds.)]. Cambridge University Press, Cambridge, United Kingdom and New York, NY, USA

Isarangkool Na Ayutthaya S., Do F.C., Pannangpetch K., Junjittakarn J., Maeght J.-L., Rocheteau A., Cochard H. 2011. Water loss regulation in mature Hevea brasiliensis: Effects of intermittent drought in the rainy season and hydraulic regulation. Tree Physiology 31:751-762.

Jacobsen A.L., Pratt R.B. 2012. No evidence for an open vessel effect in centrifuge-based vulnerability curves of a long-vesselled liana (Vitis vinifera). New Phytologist 194:982-990.

Kobayashi N., Kumagai T.o., Miyazawa Y., Matsumoto K., Tateishi M., Lim T.K., Mudd R.G., Ziegler A.D., Giambelluca T.W., Yin S. 2014. Transpiration characteristics of a rubber plantation in central Cambodia. Tree Physiology 34:285-301.
Kunjet S., Thaler P., Gay F., Chuntuma P., Sangkhasila K., Kasemsap P. 2013. Effects of Drought and Tapping for Latex Production on Water Relations of Hevea brasiliensis Trees.

Lamy J.-B., Bouffier L., Burlett R., Plomion C., Cochard H., Delzon S. 2011. Uniform selection as a primary force reducing population genetic differentiation of cavitation resistance across a species range. PloS ONE 6:e23476.

Lekawipat N., Teerawatanasuk K., Rodier-Goud M., Seguin M., Vanavichit A., Toojinda T., Tragoonrung S. 2003. Genetic diversity analysis of wild germplasm and cultivated clones of Hevea brasiliensis Muell. Arg. by using microsatellite markers. Journal of Rubber Research 6:36-47.

Maherali H., Pockman W.T., Jackson R.B. 2004. Adaptive variation in the vulnerability of woody plants to xylem cavitation. Ecology 85:2184-2199.

Manmuen S., Chantuma A., Teerawatanasuk K., Knowe S. 1993. Growth characteristic of rubber in the drought. Para Rubber Bull Thailand 13:12-30.

Markesteijn L., Poorter L., Paz H., Sack L., Bongers F. 2011. Ecological differentiation in xylem cavitation resistance is associated with stem and leaf structural traits. Plant, Cell \& Environment 34:137-148.

Meinzer F.C., Johnson D.M., Lachenbruch B., McCulloh K.A., Woodruff D.R. 2009. Xylem hydraulic safety margins in woody plants: coordination of stomatal control of xylem tension with hydraulic capacitance. Functional Ecology 23:922-930.

Pammenter N.W., Van der Willigen C. 1998. A mathematical and statistical analysis of the curves illustrating vulnerability of xylem to cavitation. Tree Physiology 18:589-593.

Pockman W.T., Sperry J.S. 2000. Vulnerability to xylem cavitation and the distribution of Sonoran desert vegetation. American Journal of Botany 87:1287-1299.

Priyadarshan P., Goncalves P.d.S. 2003. Hevea gene pool for breeding. Genetic Resources and Crop Evolution 50:101-114.

Priyadarshan P., Hoa T., Huasun H., de Gonçalves P. 2005. Yielding potential of rubber (Hevea brasiliensis) in suboptimal environments. Journal of crop improvement 14:221-247.

Purugganan M.D., Fuller D.Q. 2009. The nature of selection during plant domestication. Nature 457:843-848.

RRIT. 2011. Thai rubber statistics, RRIT.

RRIT. 2012. Khaumun wichakan yangpara [Natural rubber technical information] The agricultural co-operative federation of Thailand Printing, Bangkok.

Sangsing K., Kasemsap P., Thanisawanyangkura S., Sangkhasila K., Gohet E., Thaler P., Cochard H. 2004. Xylem embolism and stomatal regulation in two rubber clones (Hevea brasiliensis Muell. Arg.) Trees. pp. 109114.

Sparks J.P., Black R.A. 1999. Regulation of water loss in populations of Populus trichocarpa. The role of stomatal control in preventing xylem cavitation. Tree Physiology 19:453-459.

Sperry J.S., Christman M.A., Torres-Ruiz J.M., Taneda H., Smith D.D. 2012. Vulnerability curves by centrifugation: is there an open vessel artefact, and are ' $r$ ' shaped curves necessarily invalid? Plant, Cell \& Environment 35:601610. 
Thai Meteorological Department. 2014. Thailand Annual Weather Summary.

Tobin M.F., Pratt R.B., Jacobsen A.L., De Guzman M.E. 2013. Xylem vulnerability to cavitation can be accurately characterised in species with long vessels using a centrifuge method. Plant Biology 15:496-504.

Torres-Ruiz J.M., Cochard H., Mayr S., Beikircher B., Diaz-Espejo A., Rodriguez-Dominguez C.M., Badel E., Fernández J.E. 2014. Vulnerability to cavitation in Olea europaea current-year shoots: further evidence of an open-vessel artifact associated with centrifuge and air-injection techniques. Physiologia Plantarum.

Tsuda M., Tyree M.T. 1997. Whole-plant hydraulic resistance and vulnerability segmentation in Acer saccharinum. Tree Physiology 17:351-357.

Tyree M.T., Sperry J.S. 1989. Vulnerability of xylem to cavitation and embolism. Annual Review of Plant Biology 40:19-36.

Tyree M.T., Engelbrecht B.M., Vargas G., Kursar T.A. 2003. Desiccation tolerance of five tropical seedlings in Panama. Relationship to a field assessment of drought performance. Plant Physiology 132:1439-1447.

Tyree M.T., Cochard H., Cruiziat P., Sinclair B., Ameglio T. 1993. Drought-induced leaf shedding in walnut: evidence for vulnerability segmentation. Plant, Cell \& Environment 16:879-882.

Venkatachalam P., Jayasree P.K., Sushamakumari S., Jayashree R., Rekha K., Sobha S., Priya P., Kala R., Thulaseedharan A. 2007. Current perspectives on application of biotechnology to assist the genetic improvement of rubber tree (Hevea brasiliensis Muell. Arg.): An Overview. Functional Plant Science and Biotechnology 1:1-17.

Webster C.C., Baulkwill W.J. 1989. Rubber Longman Scientific \& Technical, Harlow.

Wichichonchai N., Manmeun S. 1992. Yield of rubber in the Northeastern province. Para Rubber Bull Thailand 12:81-101.

Wikberg J., Ögren E. 2004. Interrelationships between water use and growth traits in biomass-producing willows. Trees 18:70-76.

Wortemann R., Herbette S., Barigah T.S., Fumanal B., Alia R., Ducousso A., Gomory D., Roeckel-Drevet P., Cochard H. 2011. Genotypic variability and phenotypic plasticity of cavitation resistance in Fagus sylvatica L. across Europe. Tree Physiology 31:1175-1182. DOI: 10.1093/treephys/tpr101.

Zimmermann M.H. 1983. Xylem structure and the ascent of sap Springer-Verlag.

Zimmermann M.H., Jeje A.A. 1981. Vessel-length distribution in stems of some American woody plants. Canadian Journal of Botany 59:1882-1892. 